\title{
Aerosol activation and cloud processing in the global aerosol-climate model ECHAM5-HAM
}

\author{
G. J. Roelofs ${ }^{1}$, P. Stier ${ }^{2, *}$, J. Feichter ${ }^{2}$, E. Vignati ${ }^{3}$, and J. Wilson ${ }^{3}$ \\ ${ }^{1}$ Institute for Marine and Atmospheric Research Utrecht (IMAU), Utrecht University, Utrecht, The Netherlands \\ ${ }^{2}$ Max Planck Institute for Meteorology, Hamburg, Germany \\ ${ }^{3}$ Institute for the Environment and Sustainability, European Commission Joint Research Centre, Ispra, Italy \\ *California Institute of Technology, Pasadena, USA
}

Received: 20 October 2005 - Published in Atmos. Chem. Phys. Discuss.: 12 January 2006

Revised: 15 May 2006 - Accepted: 16 May 2006 - Published: 29 June 2006

\begin{abstract}
A parameterization for cloud processing is presented that calculates activation of aerosol particles to cloud drops, cloud drop size, and $\mathrm{pH}$-dependent aqueous phase sulfur chemistry. The parameterization is implemented in the global aerosol-climate model ECHAM5-HAM. The cloud processing parameterization uses updraft speed, temperature, and aerosol size and chemical parameters simulated by ECHAM5-HAM to estimate the maximum supersaturation at the cloud base, and subsequently the cloud drop number concentration (CDNC) due to activation. In-cloud sulfate production occurs through oxidation of dissolved $\mathrm{SO}_{2}$ by ozone and hydrogen peroxide. The model simulates realistic distributions for annually averaged CDNC although it is underestimated especially in remote marine regions. On average, CDNC is dominated by cloud droplets growing on particles from the accumulation mode, with smaller contributions from the Aitken and coarse modes. The simulations indicate that in-cloud sulfate production is a potentially important source of accumulation mode sized cloud condensation nuclei, due to chemical growth of activated Aitken particles and to enhanced coalescence of processed particles. The strength of this source depends on the distribution of produced sulfate over the activated modes. This distribution is affected by uncertainties in many parameters that play a direct role in particle activation, such as the updraft velocity, the aerosol chemical composition and the organic solubility, and the simulated CDNC is found to be relatively sensitive to these uncertainties.
\end{abstract}

Correspondence to: G. J. Roelofs

(g.j.h.roelofs@phys.uu.nl)

\section{Introduction}

The modification of the size distribution and chemical characteristics of an aerosol population as result of cloud drop activation, cloud drop growth and aqueous phase chemistry during a cloud event is referred to as cloud processing. Conditions at the cloud base determine how many aerosol particles become activated to cloud drops, and during the cloud lifetime these particles are subject to collision/coalescence (i.e., microphysical cloud processing; Flossmann et al., 1991) and to chemical production of non-volatile species in the cloud water, such as sulfate and organic matter (i.e., chemical cloud processing; e.g., Wurzler et al., 1997; Kreidenweis et al., 2003; Ervens et al., 2004; Bauer and Koch, 2005). The focus of this study is the chemical processing of aerosol associated with aqueous phase sulfate formation. The produced sulfate is added to the initial aerosol load of the droplet and released into the atmosphere after evaporation of the cloud.

Chemical processing tends to increase the size and solubility of aerosols, and thus changes activation properties of the aerosol (Feingold and Kreidenweis, 2002). Because this directly affects the atmospheric lifetime and transport of aerosol it must be considered when investigating climate effects of aerosol (e.g., Lohmann and Feichter, 2005). This requires an accurate prediction of the cloud drop number concentration (CDNC) and size-dependent sulfate formation in the droplets. The coupled cloud dynamical, microphysical and chemical system is characterized by spatial and temporal scales spanning several orders of magnitude (micrometers to kilometers, seconds to days). Large-scale atmospheric models cannot simulate cloud microphysics in detail, so these have to be parameterized instead. Early attempts to predict aerosol activation made use of observed correlations with sulfate amounts below the cloud base (e.g., Boucher and

Published by Copernicus GmbH on behalf of the European Geosciences Union. 
Lohmann, 1995; Roelofs et al., 1998; Jones et al., 2001). During recent years parameterizations for cloud activation have been developed that calculate CDNC based on detailed aerosol size and chemical characteristics and meteorological parameters (e.g., Abdul-Razzak and Ghan, 2000, 2002; Nenes and Seinfeld, 2003; Fountoukis and Nenes, 2005). Application of such a parameterization enables simulation of cloud drop activation in global aerosol models, consistent with the simulated meteorology and aerosol characteristics (e.g., Ghan et al., 2001).

Our study uses a similar approach, developed almost two decades ago by Hänel (1987), as a basis for a cloud processing parameterization that considers activation and cloud sulfur chemistry. As contribution to the EU project PHOENICS ("Particles of Human Origin Extinguish Natural solar Irradiance in the Climate System"; EVK2-CT-2001-00098) the parameterization is implemented in the global aerosolclimate model ECHAM5-HAM. This enables simulation of cloud sulfur chemistry in a consistent manner with aerosol activation, while the latter is simulated consistently with the modeled meteorology and aerosol characteristics. The study investigates the contribution of individual aerosol modes to cloud drop activation and in-cloud chemistry, and how both processes are related. Section 2 describes the parameterization and its implementation in ECHAM5-HAM. Section 3 presents simulated global distributions of cloud parameters and the sulfur budget, and investigates the sensitivity of simulated CDNC and sulfate distributions to the treatment of cloud processing in the model. It is shown that the currently relatively large uncertainties in aerosol characteristics and cloud updraft velocities simulated by the model may affect CDNC considerably. Hence, our study focuses more on a qualitative than quantitative investigation of the dependence between activation of aerosol and sulfur chemistry inside cloud drops. Section 4 summarizes and discusses the results.

\section{Model description}

The study is performed with a version of the coupled aerosolclimate model ECHAM5-HAM similar to the one applied by Stier et al. (2005). ECHAM5-HAM consists of the general circulation model ECHAM version 5 in which an aerosol module (HAM) is implemented that accounts for emissions of aerosol and aerosol precursors, chemical transformations, nucleation of new particles and condensation of semi-volatile $\mathrm{H}_{2} \mathrm{SO}_{4}$ on existing particles, coalescence between particles and dry and wet deposition. The core of HAM is the aerosol dynamical module M7 (Vignati et al., 2004; Wilson et al., 2001). M7 describes the aerosol population with four soluble and three insoluble aerosol modes composed of (mixtures of) sulfate, organic carbon, black carbon, sea salt and dust. The modes are lognormal and each mode is characterized by the particle number concentration and mass of asso- ciated aerosol components, from which an average dry particle radius is derived. The size ranges considered are below $0.005 \mu \mathrm{m}$ particle radius for the nucleation mode, between 0.005 and $0.05 \mu \mathrm{m}$ particle radius for the Aitken mode, between 0.05 and $0.5 \mu \mathrm{m}$ particle radius for the accumulation mode, and above $0.5 \mu \mathrm{m}$ particle radius for the coarse mode. Coalescence of unsoluble interstitial particles by cloud drops is not considered, so that only the soluble modes are relevant for this study. All emissions are treated as primary emissions except for the sulfur compounds. Hence, secondary organic aerosol (SOA) formation associated with emissions from vegetation is not calculated explicitly. Instead, all organic aerosol is emitted directly from the surface and equally divided between the Aitken and accumulation modes. The assumed fractions of organic matter attached to soluble and insoluble particles are 0.65 and 0.35 , respectively. For further information on the emission data we refer to Stier et al. (2005).

For this study we replaced the bulk cloud chemistry scheme in ECHAM5-HAM with a more detailed parameterization for cloud processing. The cloud processing parameterization is linked to the climate model's large-scale cloud scheme, which has prognostic equations for cloud liquid water and ice (Lohmann and Roeckner, 1996). For our study only the liquid phase is relevant. The parameterization consists of two steps, for cloud drop activation and for aqueous phase chemistry. First, the maximum supersaturation at the cloud base $\left(s_{m}\right)$ is estimated through an empirical approach derived from cloud parcel model simulations (Hänel, 1987). The model parameters for the lognormally distributed aerosol are used to construct discrete size distributions for the masses of each aerosol component in each of the soluble modes, which form the basis for the parameterization calculations. From $s_{m}$ the critical radius for each aerosol mode and the associated cut-off radius, i.e., the smallest dry aerosol radius activated, are calculated. CDNC is defined by the particles larger than the cut-off radius. The parameterization is presented in more detail in the Appendix. In the activation calculations it is assumed that aerosol sulfate is present as ammonium bisulfate and that sea salt consists entirely of $\mathrm{NaCl}$. Further we arbitrarily assumed that the molar weight of organic matter is represented by that of oxalic acid, that the organic matter in water-soluble particles has an arbitrary solubility of $25 \%$ regardless of drop size and that one hydrogen ion is released for each dissolved organic molecule. We note that in one of the sensitivity simulations the organic solubility is varied. The activation parameterization performs relatively accurately, i.e., the predicted supersaturation and CDNC are generally within $30 \%$ of cloud parcel model results. Discrepancies can be larger when the aerosol is almost unsoluble and when updraft velocities are several $\mathrm{m} / \mathrm{s}$ or larger, but for large-scale clouds such updrafts are not simulated.

The vertical velocity is calculated from the large scale updraft velocity and the turbulent kinetic energy (TKE) 
provided by the climate model as proposed by Lohmann et al. (1999). However, the derived vertical velocities were rather large at the relatively coarse horizontal resolution applied in our study (T21, 5.6 $6^{\circ}$, exceeding $0.9 \mathrm{~m} / \mathrm{s}$ for $50 \%$ of the cloud events. Observations indicate that $0.5 \mathrm{~m} / \mathrm{s}$ is a more realistic value for this (Guo et al., 2004). By scaling the square root of TKE in the formulation by Lohmann et al. (1999) by 0.25 , the updraft velocities are more in agreement with the observations. We also examine the sensitivity of simulated CDNC for the updraft velocity in the sensitivity analysis.

In our study CDNC reflects the results of aerosol activation, and its value is not influenced by collision/coalescence. The parameterization results do not feed back on the simulated large-scale cloud evolution and precipitation formation in order to carry out the comparison between different simulations in absence of meteorological differences. On the other hand, the simulated activated aerosol number and mass are directly used for consistent treatment of rainout of aerosol from the cloud. Wet deposition associated with the ice phase and below-cloud scavenging of aerosol is simulated in the same way as in Stier et al. (2005, their Table 3). In-cloud scavenging of interstitial particles is not considered.

The second step in the parameterization calculates incloud sulfate formation and its distribution over the different activated modes, i.e., the modes that contribute to CDNC. The initial acidity of droplets is determined by the chemical composition of the particles. The parameterization uses the liquid water content from the cloud scheme, together with CDNC, to calculate an average cloud drop radius. Since the distribution of cloud water acidity over the droplet population influences the efficiency of $\mathrm{pH}$-dependent chemical reactions such as the oxidation of $\mathrm{SO}_{2}$ by $\mathrm{O}_{3}$ (Roelofs, 1993), two bins are considered for each activated mode. One is for the smallest activated particles that are characterized by relatively high degree of dilution and low ion concentrations, and one is for the largest activated particles that have relatively high ion concentrations. We performed the aqueous phase sulfur chemistry calculations with varying distributions of the cloud water between both bins and compared the parameterized sulfate production with simulations of our cloud parcel model (Roelofs and Jongen, 2004). It was found that the in-cloud production of sulfate was approximated to within several percent when the fraction of the LWC in the diluted and concentrated bins is around $75 \%$ and $25 \%$, respectively, relatively independent of aerosol type and updraft velocity.

The cloud chemistry module is similar to that in the global sulfur cycle study of Roelofs et al. (1998). It calculates dissolution of $\mathrm{SO}_{2}, \mathrm{O}_{3}, \mathrm{H}_{2} \mathrm{O}_{2}$ and $\mathrm{HNO}_{3}$, dissociation of dissolved $\mathrm{SO}_{2}$ and $\mathrm{HNO}_{3}$, and aqueous phase oxidation of $\mathrm{S}(\mathrm{IV})$ to sulfate by $\mathrm{O}_{3}$ and $\mathrm{H}_{2} \mathrm{O}_{2}$. In the present study offline oxidant fields are used. In Roelofs et al. (1998) oxidant chemistry and the sulfur cycle were calculated simultaneously. They showed that when $\mathrm{H}_{2} \mathrm{O}_{2}$ is calculated together with the sulfur cycle the simulated in-cloud oxidation
Table 1. Simulated and observed (italics, Han et al., 1994) effective cloud drop radius $(\mu \mathrm{m})$.

\begin{tabular}{lrrrr}
\hline & \multicolumn{2}{c}{ DJF } & \multicolumn{2}{c}{ JJA } \\
\hline NH land & 9.7 & 7.6 & 10.9 & 9.0 \\
SH land & 10.5 & 9.3 & 9.3 & 9.1 \\
NH ocean & 15.2 & 10.2 & 16.1 & 12.2 \\
SH ocean & 17.8 & 11.6 & 17.5 & 11.6 \\
\hline
\end{tabular}

by $\mathrm{H}_{2} \mathrm{O}_{2}$ is smaller than when $\mathrm{H}_{2} \mathrm{O}_{2}$ is calculated without the sulfur cycle. Therefore, we use their monthly distributions for $\mathrm{H}_{2} \mathrm{O}_{2}$ as well as for $\mathrm{HNO}_{3}$. Note that the effect of $\mathrm{HNO}_{3}$ on activation of particles (Kulmala et al., 1993) is not considered in our study. For ozone and $\mathrm{OH}$ the same monthly distributions are applied as in Stier et al. (2005).

Data presented in this study are compiled from four years of simulation in the T21 resolution (approximately $5.6^{\circ} \times 5.6^{\circ}$ with a $2400 \mathrm{~s}$ time step). The model uses 19 vertical layers in a hybrid $\sigma$-p-coordinate system, from the surface to $10 \mathrm{hPa}$. The simulated meteorology is generated by the climate model and does not reflect actual meteorological events.

\section{Results}

\subsection{Cloud microphysics}

Figure 1 displays the globally and annually averaged incloud CDNC. The distribution is obtained by sampling the model domain as from a satellite, i.e., using the highest cloudy grid box from each model column, but at altitudes below $500 \mathrm{hPa}$ and with a cloud cover larger than $10 \%$. The simulated annual CDNC is between 100 and $450 \mathrm{~cm}^{-3}$ (ambient air pressure) in continental air and outflow regions, and between 5 and $25 \mathrm{~cm}^{-3}$ in remote marine regions. The annually averaged supersaturation is $0.1-0.5 \%$ over the continents and between $0.5-1.5 \%$ over the oceans, reflecting the different aerosol abundances in continental and marine atmospheres.

Table 1 compares seasonally averaged effective radii from the simulation with observations derived from AVHRR (Han et al., 1994). In the calculation of the cloud drop effective radius, $r_{\text {eff }}$, we use a value of 0.75 for the cube ratio between the mean volume radius and the effective radius of the cloud drop spectrum (Boucher and Lohmann, 1995; Roelofs et al., 1998). Over the continents the simulated $r_{\text {eff }}$ is 1 to $2 \mu \mathrm{m}$ larger than observed, although in the SH for JJA, when emissions from biomass burning play a role, it is relatively close to the observed value. Assuming that the simulated LWC is relatively accurate, the discrepancies suggest that CDNC should be larger by approximately $50 \%$ in the summer seasons and by $100 \%$ in the NH during winter. There may be 


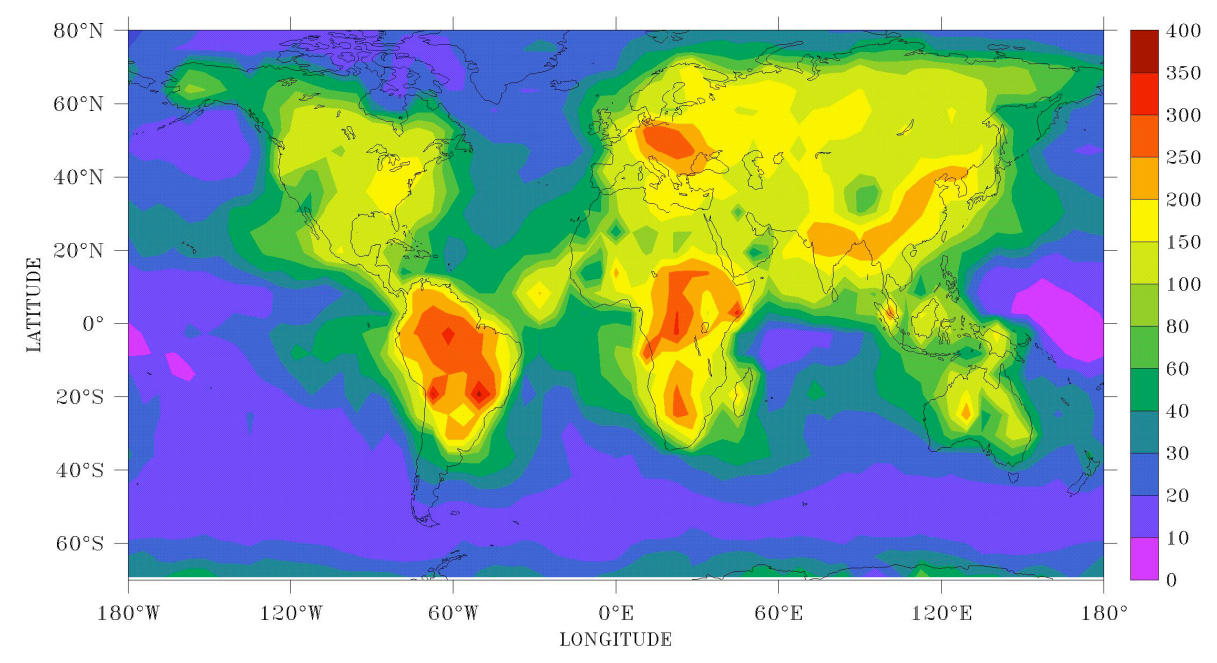

Fig. 1. Global distribution of annually averaged $\mathrm{CDNC}\left(\mathrm{cm}^{-3}\right)$. CDNC is sampled as from a satellite, using the highest cloudy grid box below $500 \mathrm{hPa}$ from each model column.

different causes for the underestimation, e.g., associated with the simulated size distribution of the aerosol mass, with the aerosol solubility and with the vertical velocity. Further, it was recently found that isoprene may act as SOA precursor in the gas phase under high $\mathrm{NO}_{\mathrm{x}}$ conditions (Kroll et al., 2005 ) or by organic reactions in the aqueous phase (Lim et al., 2005) but this is not considered in the emission data. We note that the value of the water vapor accommodation coefficient is of large significance for the simulation of CDNC (Lance et al., 2004; Kreidenweis et al., 2003). In our study a value of 1 is used, but smaller values, associated with less efficient condensation and larger CDNC, may be more realistic (Meskhidze et al., 2005). Reduction of CDNC (or growth of $\left.r_{\text {eff }}\right)$ due to autoconversion of cloud drops is not considered in our model. Given the fact that on average $10 \%$ of the clouds actually produce precipitation (Lelieveld and Crutzen, 1990) this may have some impact on the validation of CDNC but a modest effect on $r_{\text {eff }}$. However, the autoconversion process would further increase the discrepancy between the modelled and observed $r_{\text {eff }}$, so that it can not explain the present discrepancies. The enhancement of aerosol activation due to $\mathrm{HNO}_{3}$ uptake by unactivated aerosol, which is also not considered here, may increase CDNC values in polluted areas by 5 to $10 \%$ (Roelofs and Jongen, 2004).

Cloud drop radii are overestimated in marine regions. Comparison of simulated and observed $r_{\text {eff }}$ suggests that the simulated clean marine CDNC $\left(10-50 \mathrm{~cm}^{-3}\right.$, see Fig. 1) is smaller by a factor 3 or 4 than observed marine cloud drop concentrations, generally ranging between 50 and 300 drops $\mathrm{cm}^{-3}$ (Boucher and Lohmann, 1995 and references therein). There may be several reasons for this. The concentration of emitted sub-micron sea salt may be underestimated, and neglect of emission of organic matter from the ocean surface may further contribute to the discrepancies (O'Dowd et al.,
2004). Note that other recent global aerosol simulations that do not take these emissions into account also underestimate the concentration of cloud condensation nuclei in marine air (Ghan et al., 2001; Spracklen et al., 2005). Further, errors in aerosol and aerosol precursor transport associated with the relatively low spatial resolution in our study cannot be excluded. Also, the model overestimates the strength of the hydrological cycle and local precipitation in tropical marine regions (Hagemann et al., 2006), so that wet deposition of particles may be too efficient.

\subsection{The sulfur cycle}

Table 2 shows the computed annual and global sulfur budget. Most important atmospheric sulfur sources considered by the model are marine emissions of DMS (23.4 Tg S/yr) and anthropogenic $\mathrm{SO}_{2}$ emissions associated with industry, and with fossil fuel and biofuel use (54.2 Tg S/yr). Around $25 \%$ of the $\mathrm{SO}_{2}$ is removed from the atmosphere by dry and wet deposition, while the rest is transformed to sulfate, in the gas phase by $\mathrm{OH}$ and in the aqueous phase by $\mathrm{H}_{2} \mathrm{O}_{2}$ and $\mathrm{O}_{3}$. The spatial distribution of sulfate formation in the aqueous phase, shown in Fig. 2, reflects the major sulfur emission areas and the continental outflow regions. We remark that our simulated sulfate distribution is similar to the one simulated and evaluated by Stier et al. (2005, their Fig. 2a). Aqueous phase oxidation by $\mathrm{H}_{2} \mathrm{O}_{2}$ is the dominant pathway for sulfate formation. The modeled sulfur budget generally falls within the range compiled from several sulfur cycle model studies by Rotstayn and Lohmann (2002).

Table 2 also lists results from two previous studies. Roelofs et al. (1998) used version 4 of ECHAM, coupled to a sulfur cycle and oxidant chemistry module. Their $\mathrm{SO}_{2}$ emissions differ somewhat from those used in the present study. 
Table 2. Global and annual sulfur budget.

\begin{tabular}{lccc}
\hline & This study & Roelofs et al. (1998) & Stier et al. (2005) \\
\hline $\mathrm{SO}_{2}$ emis/prod (Tg/y) & 91.2 & 90 & 92.0 \\
$\mathrm{SO}_{2}$ deposition (Tg/y) & 22.9 & 16 & 18.9 \\
$\mathrm{SO}_{2}$ chem loss (Tg/y) & 68.2 & 74 & 73.1 \\
oxidation by $\mathrm{OH}(\%)$ & 23.3 & 22 & \\
by $\mathrm{H}_{2} O_{2}(\%)$ & 61.8 & 59 & \\
by $\mathrm{O}_{3}(\%)$ & 14.9 & 19 & \\
& & & \\
$\mathrm{SO}_{4}$ source/sink (Tg/y) & 70.0 & 78 & 76.1 \\
$\mathrm{SO}_{2}$ burden $(\mathrm{Tg})$ & 0.85 & 0.61 & 0.67 \\
$\mathrm{SO}_{4}$ burden $(\mathrm{Tg})$ & 0.78 & 0.96 & 0.80 \\
\hline
\end{tabular}

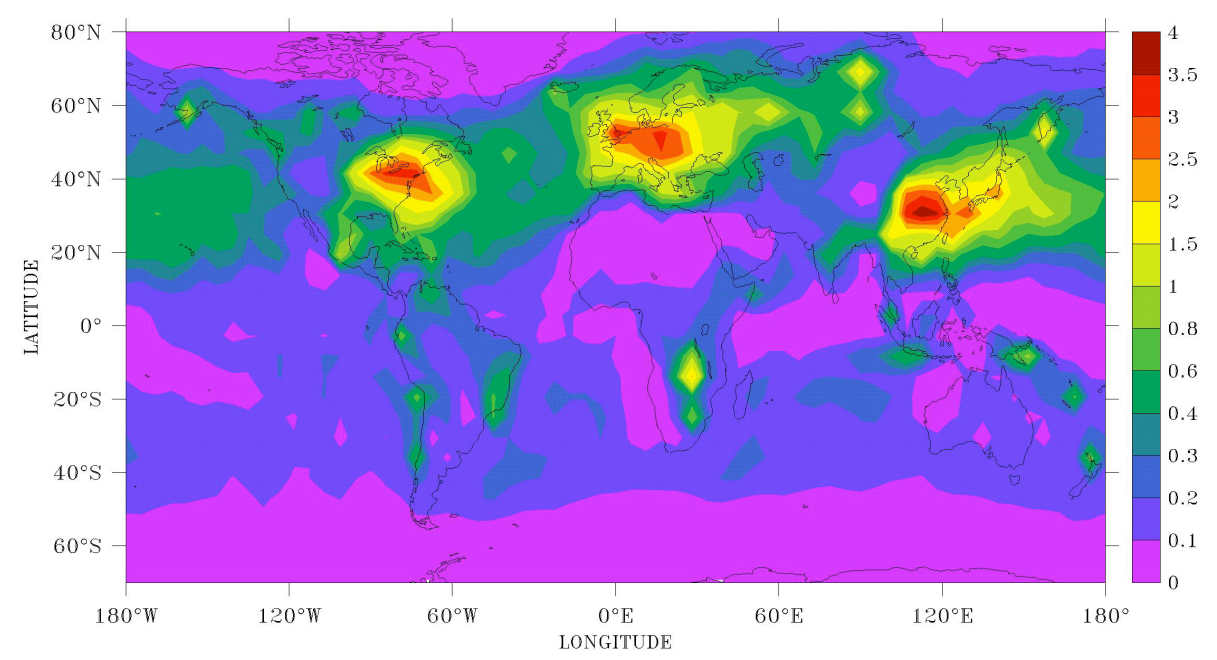

Fig. 2. Global distribution of annually averaged atmospheric columns of sulfate produced in cloud drops $\left(\mathrm{mg} \mathrm{m}^{-2} \mathrm{day}^{-1}\right)$.

The anthropogenic $\mathrm{SO}_{2}$ emssions are larger by $\sim 13 \mathrm{Tg} \mathrm{S} / \mathrm{yr}$, but the natural emissions of ocean DMS and volcanic $\mathrm{SO}_{2}$ are smaller, each by $\sim 7 \mathrm{Tg} / \mathrm{yr}$. Roelofs et al. (1998) calculate a more efficient oxidation by $\mathrm{O}_{3}$, partly due to the fact that acidity from dissolved organics is not accounted for in their study. Further they assume that a fixed $60 \%$ of the aerosol ammonium bisulfate is incorporated into cloud drops through activation. The present study yields an average activation efficiency for the soluble accumulation mode mass in the order of $80-95 \%$ over continents and up to $100 \%$ over the tropical ocean. For the coarse mode it exceeds $98 \%$ while for the Aitken mode it is generally below $40 \%$.

Stier et al. (2005), who also apply ECHAM5-HAM, use a relatively simple cloud processing method, which considers bulk chemistry (i.e., all cloud drops are considered to have the same chemical composition) and redistributes the produced sulfate over the accumulation and coarse mode proportionally to the number concentration. They do not con- sider acidity from dissolved organic matter and from $\mathrm{HNO}_{3}$. They simulate more efficient oxidation of $\mathrm{SO}_{2}$, partly attributable to the different acidity and its influence on $\mathrm{SO}_{2}$ oxidation by $\mathrm{O}_{3}$ and partly to the different $\mathrm{H}_{2} \mathrm{O}_{2}$ distributions used. Our atmospheric $\mathrm{SO}_{2}$ burden is therefore somewhat larger. Simulated sulfate burdens are similar whereas Roelofs et al. (1998) simulate a higher sulfate burden. The difference may be explained by the fact that the simulated sulfate burden is highly sensitive to the simulation of wet deposition (Rotstayn and Lohmann, 2002; Roelofs et al., 2001).

\subsection{Modal contributions to CDNC and sulfate formation}

Figure 3 shows the fractional contribution of the activated modes to CDNC. Nucleation mode particles require relatively high supersaturations to activate, and their contribution to CDNC is negligible. The accumulation mode dominates throughout most of the globe, with highest contributions 

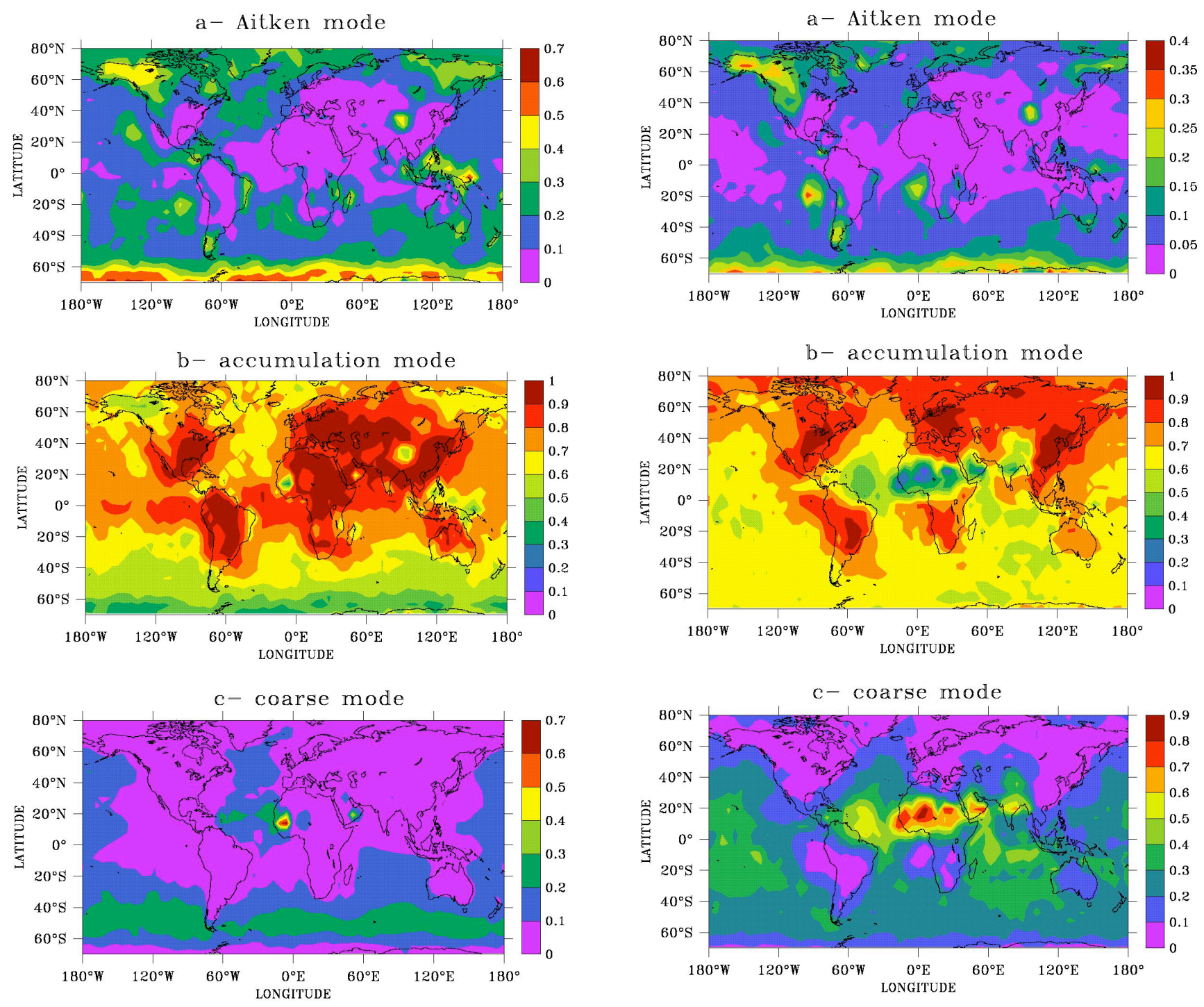

Fig. 3. Relative contribution to annually averaged CDNC by cloud drops growing on particles from (a) the Aitken mode, (b) the accumulation mode, and (c) the coarse mode.

( $>80 \%$ ) in (sub-)tropical regions. The coarse mode contributes about $20 \%$ over most of the oceans, maximizing at about $30 \%$ in the SH storm track where sea salt aerosol is abundant, and also at $30 \%$ over the $\mathrm{NH}$ subtropical Atlantic Ocean associated with Sahara dust transport. The coarse mode contribution is relatively small over the continents. The Aitken mode particles contribute most significantly at high latitudes in the $\mathrm{NH}$ and $\mathrm{SH}(30-50 \%)$ and over the oceans (15-30\%).

Figure 4 shows the fractional contribution of each activated mode to the annual aqueous sulfate production. Again, the dominant contribution is from the accumulation mode. The contribution by droplets originating from the Aitken mode is relatively small because activation of Aitken particles mainly occurs in remote regions. The contribution to

Fig. 4. Relative contribution to annually averaged in-cloud sulfate formation by cloud drops growing on particles from (a) the Aitken mode, (b) the accumulation mode, and (c) the coarse mode.

sulfate by the activated coarse mode is relatively large due to efficient sulfate production in sea salt drops over the oceans and drops growing on coated dust particles over Africa and southern Asia.

\subsection{Size-dependent sulfate formation}

The foregoing shows that the modal contributions to CDNC and sulfate production are spatially highly variable. In this and the next section the interaction between size- (or modal-) dependent sulfur chemistry and aerosol activation is investigated in more detail. Since most sulfur emissions occur in the Northern Hemisphere and the representativity of simulated parameters in the Southern Hemisphere is strongly determined by inaccuracies in the treatment of 
organic aerosol, we focus on the Northern Hemisphere. We performed two simulations (A1, A2) with the same cloud activation calculations as in the control simulation (CTRL) but without consideration of cloud chemistry in the activated Aitken (A1) and coarse (A2) modes. The simulated aqueous sulfate production and CDNC, averaged over the Northern Hemisphere, and the modal contributions are shown in Table 3 .

In CTRL about $2.1 \mathrm{Tg} \mathrm{S} / \mathrm{yr}$ of sulfate is produced in the activated Aitken mode, mostly close to source areas and in continental outflow regions. In A1 this is almost completely compensated for by excess sulfate formation in the activated accumulation $(+1.5 \mathrm{Tg} \mathrm{S} / \mathrm{yr})$ and coarse $(+0.5 \mathrm{Tg} \mathrm{S} / \mathrm{yr})$ modes. The hemispheric sulfate burden does not change significantly compared to CTRL, nor does the sulfate column distribution (not shown here). Apparently, a change in sulfate formation in one mode is efficiently compensated for by an opposite change in other modes or by gas phase sulfate formation within a relatively short time.

The average CDNC, on the other hand, decreases with 15 drops $/ \mathrm{cm}^{3}$ or $20 \%$, because less particles from the Aitken and accumulation modes are activated. The activation of coarse mode aerosol occurs at relatively small supersaturation and is not affected much. There are two causes for the CDNC decrease. Due to neglect of in-cloud chemistry in the activated Aitken mode in A1 the particles remain less soluble than in CTRL, which is reflected in a smaller activation efficiency. The accumulation mode has become more soluble, and Köhler theory would predict enhanced particle activation for this mode. However, Table 3 shows the opposite. Examination of the detailed model results shows that the total particle concentrations in the Aitken and accumulation modes also have changed. The Aitken mode particles in A1 are not subject to chemical growth during the cloud phase, and this reduces the growth of Aitken mode aerosol to the accumulation mode size. As a result, the Aitken mode particle concentration is larger in A1 than in CTRL, up to $25 \%$ over the $\mathrm{NH}$ continents and up to $80 \%$ over the $\mathrm{NH}$ oceans, while the accumulation mode particle concentration is smaller by approximately $20 \%$. However, also the sum of the Aitken and accumulation mode particle concentrations is larger in A1, up to $50 \%$ over the $\mathrm{NH}$ ocean. This indicates a smaller coagulation efficiency for Aitken mode particles in A1, and this further reduces the transfer of particle mass and number to the accumulation mode. The results indicate that cloud processing of particles from the smaller modes is an efficient mechanism for particle growth and results in a larger concentration of accumulation mode particles and CCN. Evidently, this also influences the condensation of low-volatile $\mathrm{H}_{2} \mathrm{SO}_{4}$ on the individual aerosol modes, making the relation between in-cloud chemistry and aerosol activation highly complex and non-linear. Differences between CTRL and A1 maximize during winter when gas phase production and condensation of $\mathrm{H}_{2} \mathrm{SO}_{4}$, another important growth mechanism for Aitken mode particles, minimize.
Table 3. Annual aqueous phase sulfate production and CDNC averaged over the Northern Hemisphere for the control simulation (CTRL) and sensitivity simulations A1 and A2, with contributions from the different modes and chemical pathways.

\begin{tabular}{lrrr}
\hline & CTRL & $\mathrm{A} 1$ & $\mathrm{~A} 2$ \\
\hline SO $_{4}$ production (Tg S) & 51.4 & 51.3 & 50.6 \\
contribution (Tg S) by: & & & \\
Aitken mode & 2.1 & 0.0 & 2.2 \\
accumulation mode & 31.9 & 33.4 & 36.7 \\
coarse mode & 6.0 & 6.5 & 0.0 \\
gas phase OH & 11.4 & 11.4 & 11.7 \\
& & & \\
CDNC $\left(\mathrm{cm}^{-3}\right.$ ) & 74.4 & 60.7 & 74.8 \\
contribution (cm & \\
Aitken mode & & & \\
accumulation mode & 10.9 & 7.2 & 10.8 \\
coarse mode & 60.6 & 50.6 & 61.0 \\
& 3.0 & 3.0 & 3.0 \\
\hline
\end{tabular}

In simulation A2 the activated coarse mode is excluded from aqueous phase chemistry calculations. The sulfate produced in this mode in CTRL, $6.0 \mathrm{Tg} \mathrm{S} / \mathrm{yr}$, is in A2 mostly distributed over the activated accumulation $(+4.8 \mathrm{Tg} \mathrm{S} / \mathrm{yr})$ and Aitken $(+0.1 \mathrm{Tg} \mathrm{S} / \mathrm{yr})$ modes. The remaining $\mathrm{SO}_{2}(1.1 \mathrm{Tg}$ $\mathrm{S} / \mathrm{yr}$ ) is oxidized in the gas phase or added to the $\mathrm{SO}_{2}$ deposition flux. The impact on CDNC is very small. Coarse mode aerosol is already relatively soluble so that the in-cloud produced sulfate has a negligible additional effect on activation. Secondly, the effects are most prominent in oceanic regions where generally more than $80 \%$ of the accumulation mode particles are activated in our model, and the additional sulfate in A2 has only a small impact on this. Again, the simulated sulfate column distribution does not differ significantly from CTRL.

\subsection{Sensitivity studies}

The previous section showed that the mode-specific distribution of in-cloud formed sulfate affects the aerosol size distribution and therefore CDNC. Many parameters that play a role in cloud formation and chemistry co-determine the distribution of the available liquid water and acidity over the activated modes and, with that, the sulfate formation efficiency. To assess the magnitude of this influence we have performed five sensitivity studies that more or less reflect uncertainties in the cloud processing input parameters. The results are shown in Table 4. In all sensitivity simulations the sulfate columns do not differ significantly from CTRL, as was the case for $\mathrm{A} 1$ and $\mathrm{A} 2$.

In B1, B2 and B3 the boundary conditions for the aqueous phase chemistry calculations are altered, by reducing atmospheric $\mathrm{HNO} 3$ concentrations to $25 \%$ of the CTRL values (B1), by reducing $\mathrm{H}_{2} \mathrm{O}_{2}$ and ozone to $80 \%$ (B2), and by not 
Table 4. Annual NH sulfur budgets for the control simulation (CTRL) and sensitivity simulations ${ }^{\mathrm{a}}$.

\begin{tabular}{lrrrrrr}
\hline & CTRL & B1 & B2 & B3 & B4 & B5 \\
\hline SO $_{4}$ production (Tg S/y) & 51.4 & 51.9 & 50.3 & 51.4 & 51.3 & 51.4 \\
& & & & & & \\
contribution (Tg S) by: & & & & & & \\
Aitken mode & 2.1 & 1.9 & 2.1 & 2.2 & 2.4 & 2.2 \\
accum. mode & 31.9 & 32.6 & 30.7 & 31.6 & 31.6 & 31.9 \\
coarse mode & 6.0 & 6.1 & 5.8 & 6.2 & 6.0 & 5.8 \\
gas phase OH & 11.4 & 11.3 & 11.7 & 11.4 & 11.4 & 11.4 \\
& & & & & & \\
CDNC $\left(\mathrm{cm}^{-3}\right.$ ) & 74.4 & 73.4 & 75.3 & 75.1 & 77.7 & 76.9 \\
$\begin{array}{l}\text { contribution (cm } \\
\text { Aitken mode }\end{array}$ & 10.9 & 10.8 & 11.1 & 10.9 & 12.9 & 11.8 \\
$\begin{array}{l}\text { accumulation mode } \\
\text { coarse mode }\end{array}$ & 60.6 & 59.7 & 61.0 & 61.3 & 61.8 & 62.1 \\
\hline
\end{tabular}

a) B1: decrease $\mathrm{HNO}_{3}$ to 25\%; B2: decrease oxidants to 80\%; B3: bulk approach for chemistry for each mode; B4: 75\% solubility of aerosol organic matter; B5: vertical velocities are increased by $10 \%$.

distinguishing between more and less diluted drops within each activated mode during chemistry calculations, the socalled bulk approach (B3). In a bulk approach no distinction is made between different chemical environments in more or less concentrated droplets. This may lead to inaccuracies in the calculated chemical yield of $\mathrm{pH}$-dependent chemical reactions such as the oxidation of dissolved $\mathrm{SO}_{2}$ by ozone. Each of the perturbations results in a different distribution of in-cloud sulfate formation over the individual modes, either directly through oxidant concentrations or indirectly through the acidity. Consistent with Sect. 3.4, an increase (decrease) of in-cloud sulfate formation in the activated Aitken mode results in a larger (smaller) average concentration of accumulation mode particles, and a larger (smaller) CDNC. The decrease in sulfate formation in B3 is relatively small compared to model studies that indicate that a bulk approach significantly underestimates sulfate formation (Hegg and Larson, 1990; Roelofs, 1993, Kreidenweis et al., 2003). These studies, however, focus on single cloud events while our study focuses on longer time scales where air masses undergo several subsequent cloud cycles. Nevertheless, the small differences suffice to significantly affect CDNC.

In B4 and B5 the particle activation efficiency is changed directly. In B4 the solubility of the organic matter in watersoluble aerosol is increased from $25 \%$ to $75 \%$. This enhances activation of Aitken and accumulation mode particles. Due to the acidity of the organic matter assumed in the simulations, the oxidation of $\mathrm{SO}_{2}$ by ozone in the activated accumulation mode is less efficient. Enhanced sulfate production inside droplets that originate from the Aitken mode compensates for this. The enhanced cloud processing of this mode results in more efficient particle growth and a larger accumulation mode particle concentration, and this results in a larger average CDNC. In B5 we increased the simulated ver- tical velocity by $10 \%$, although this perturbation is relatively small compared to the actual uncertainties due to the sub-grid scale on which cloud formation occurs. A higher vertical velocity yields a larger CDNC, mostly because of activation of more and smaller particles from the Aitken and accumulation modes. This causes a shift in the in-cloud sulfate production towards the smaller mode, and leads to an enhancement of CDNC.

The sensitivity of the hemispherically averaged CDNC may appear relatively small from the data in Table 4, but the spatial variability is relatively large. Largest changes compared to CTRL occur over the continents close to emission areas, and are approximately $-8 \%$ for $\mathrm{B} 1,+6 \%$ for $\mathrm{B} 2$ and $\mathrm{B} 3$, and $+20 \%$ for B4 and B5. Over the oceans CDNC is less sensitive to perturbations because the particle concentrations available for activation are relatively small and therefore a limiting factor.

To qualitatively explore the influence of mode-dependent cloud processing on an aerosol indirect forcing we performed another model run with $75 \%$ organic solubility as B4, but without consideration of in-cloud chemistry in activated Aitken particles, as A1. The NH annually averaged CDNC for this simulation is $65.1 \mathrm{~cm}^{-3}$ while CDNC in A1 with $25 \%$ organic solubility is $60.7 \mathrm{~cm}^{-3}$. So, due to a change in organic solubility CDNC increases by $4.4 \mathrm{~cm}^{-3}$ or $\sim 7 \%$. In the full chemistry simulations (B4 vs. CTRL, see Table 4) CDNC changes from 74.4 to $77.7 \mathrm{~cm}^{-3}$, an increase of $3.3 \mathrm{~cm}^{-3}$ or $4.5 \%$. Hence, the treatment of cloud processing not only affects the magnitude of simulated CDNC but also the magnitude of the forcing associated with a perturbation of input parameters. 


\section{Conclusions and discussion}

We presented simulations of CDNC and in-cloud sulfate formation with the coupled aerosol-climate model ECHAM5HAM. The model employs a cloud processing parameterization that estimates the maximum supersaturation at the cloud base, based on the simulated aerosol size and chemical properties and meteorology. Then, CDNC is derived and in-cloud sulfur chemistry is calculated. The activated aerosol number and mass calculated by the parameterization enable a consistent treatment of the wet removal of aerosol from clouds.

The simulated annual distribution of column sulfate is similar to that of Stier et al. (2005) who also apply ECHAM5HAM but with a relatively simple cloud processing scheme. In general we found that the simulated atmospheric sulfate distribution is relatively insensitive to the treatment of cloud processing or uncertainties associated with the input parameters. The relatively short atmospheric lifetime of $\mathrm{SO}_{2}$ enables efficient compensating effects between different oxidation pathways and the activated modes.

The model results indicate a strong link between the simulation of cloud processing and of CDNC. The in-cloud produced sulfate modifies the size and solubility of particles, especially of the Aitken mode. In our simulations in-cloud sulfate formation in activated Aitken particles acts as an important source of accumulation mode particles and cloud condensation nuclei, either directly by chemical growth due to sulfate production inside cloud drops or indirectly through particle coagulation after the cloud event. The magnitude of this source depends on the produced sulfate amount and how it is distributed over the activated modes. Our study shows that many parameters that play a role in cloud formation also affect this distribution. This includes some of the initial assumptions applied in our study, such as the neglect of explicit ammonia chemistry which changes cloud water acidity, and of the autoconversion process which affects the liquid water associated with the separate modes. The assumptions and uncertainties may have a significant influence on the simulated CDNC. Therefore, through its effect on CDNC cloud processing may also influence precipitation formation (Albrecht, 1989; Roelofs and Jongen, 2004).

CDNC is evaluated through the simulated cloud drop effective radius which is calculated using the simulated LWC. Discrepancies between modelled and observed SW and LW cloud forcings suggest that the amount of low clouds may be overestimated in the model (Wild and Roeckner, 2006). It is not clear whether the overestimation involves liquid or ice clouds, or is associated with the cloud cover or the cloud lifetime. Assuming that simulated LWC is relatively accurate, the comparison of the simulated cloud drop effective radius with observations indicates that the average modeled CDNC over the continents is of the right order of magnitude, albeit somewhat underestimated. Over remote oceanic regions CDNC is underestimated by a factor 3 to 4 . The parameterization of the maximum supersaturation at cloud base may contribute to the error in the simulated CDNC. The estimated accuracy of the parameterized CDNC is within $30 \%$ when compared to parcel model simulations (Hänel, 1987). Recently it was found that similar parameterizations perform relatively well compared with observed CDNC, within $\sim 30 \%$ (Meskhidze et al., 2005). These errors, however, are too small to fully explain the discrepancies between model and observations, and our study shows that other model uncertainties have a comparable impact on CDNC, either directly through their impact on particle activation properties or indirectly through cloud chemical processes. SOA formation is not considered in the present model version, and this may contribute to an underestimation of the aerosol particle concentration and size in remote regions (Maria et al., 2004). In-cloud production of non-volatile organic species which are not considered in our study may further contribute to the cloud processing of aerosol and to CDNC (Ervens et al., 2004, Lim et al., 2005). Other sources of large uncertainty are associated with, for example, the updraft velocity at the cloud base, the water vapor accommodation coefficient applied in the simulations, or the amount of SOA precursors emitted from vegetation. Further model studies of observed events of cloud formation and chemistry are required to fully explore the influence of meteorological and chemical parameters and their uncertainties on cloud optical characteristics and cloud forcing on regional and global scales.

\section{Appendix A}

The calculation of the concentration of activated aerosol particles upon cloud formation proceeds according to the parameterization developed by Hänel (1987). First, the model parameters that describe the log-normally distributed aerosol are used to construct a log-normal binned size distribution for the soluble matter associated with each of the soluble modes. Each distribution consists of 70 bins between 0.001 and $2 \mu \mathrm{m}$ dry particle radius. Let subscript $i$ indicate the mode. $B_{i}$ is the factor needed for the Raoult term in the Köhler equation (Pruppacher and Klett, 1997), which is derived from the simulated molar quantities of sulfate, organics and sea salt contained in mode $i$. An average $B$, representing all soluble aerosol within the four soluble modes, is calculated from $B_{i}$ according to:

$B=\frac{\sum_{i=1,4} B_{i} n_{i+}}{n_{+}}$

with

$n_{i+}=\sum_{j=1,70} n_{i, j} r_{i, j}^{3 / 2}$ and $n_{+}=\sum_{i=1,4} n_{i+}$

Subscript $i, j$ denotes the $j$-th bin in the size distribution of mode $i$, and $n_{i, j}$ and $r_{i, j}$ are associated particle number concentration and wet radius (unit: $\mathrm{cm}$ ) of particles. Because 
the effect of organics on the surface tension (Facchini et al., 1999) is not considered the factor for the Kelvin term in the Köhler equation, $A$, is the same for all particles. Then the maximum supersaturation at the cloud base $\left(s_{m}\right)$ is estimated through an empirical approach derived from cloud parcel model simulations:

$s_{m}=F \frac{X w+(2 A / 3) n_{s g}\left(s_{m}\right)-(A / 3 B)^{5 / 2} B n_{-}\left(s_{m}\right)}{(3 B / A)^{1 / 2} n_{+}\left(s_{m}\right)+(A / 3 B) n_{s g}\left(s_{m}\right)}$

with $w$ the updraft velocity in $\mathrm{cm} \mathrm{s}^{-1}$, and

$X=\exp \left(-6.639-0.03795 \mathrm{~T}+0.00005425 \mathrm{~T}^{2}\right)$

$n_{+}\left(s_{m}\right)=\sum_{i=1,4} \sum_{r_{i, j}>r_{c, i}\left(s_{m}\right)} n_{i, j} r_{i, j}^{3 / 2}$

$n_{-}\left(s_{m}\right)=\sum_{i=1,4} \sum_{r_{i, j}>r_{c, i}\left(s_{m}\right)} n_{i, j} r_{i, j}^{-3 / 2}$

$n_{s g}\left(s_{m}\right)=\sum_{i=1,4} \sum_{r_{i, j}>r_{c, i}\left(s_{m}\right)} n_{i, j}$

and $A$ in $\mathrm{cm}$. T is temperature, and $r_{c, i}\left(s_{m}\right)$ is the cut-off radius (i.e., the smallest dry particle size that becomes activated) for mode $i$ at $s_{m}$. Several assumptions are made in the derivation of the approximation for $\left.s_{m}: 1\right)$ interstitial particles do not contribute to the change in liquid water content at the time that $s_{m}$ occurs since they are practically in equilibrium; 2) non-continuum effects are removed from the diffusion-heat conduction parameter; 3 ) the relative humidity is replaced by a linear approximation; and 4) critical radii are considered instead of actual radii. The first three assumptions do not significantly affect the accuracy of the parameterization, especially when compared with other model inaccuracies as discussed in Sect. 4. The last assumption introduces a relatively large inaccuracy because it neglects the different specific times for supersaturation change and droplet growth, leading to kinetic growth limitation for relatively large particles (e.g., Nenes and Seinfeld, 2003). $F$ is an empirical correction factor to correct for this:

$F=a w^{b}(1-0.1 \times \ln w)$

with

$$
\begin{aligned}
a & =0.1 \times\left(B+\frac{n_{+}}{3 \times 10^{8} n_{s}}\right) \\
& +\exp \left(-129.168-11.6415 Y-0.3440 Y^{2}-0.003313 Y^{3}\right) \\
b & =-2.5873-0.5516 Z-0.030 Z^{2}-0.000479 Z^{3} \\
Y & =\ln \left(B n_{+}^{2} / n_{s}\right) \text { with }-37.3 \leq Y \leq-22.3 \\
Z & =\ln \left(B n_{+}^{5 / 3} / n_{s}^{2 / 3}\right) \text { with }-47.1 \leq Z \leq-31.8
\end{aligned}
$$

$n_{s}=\sum_{i=1,4} \sum_{j=1,70} n_{i, j}$

Values for $s_{m}, n_{s g}\left(s_{m}\right), n_{+}\left(s_{m}\right)$ and $n_{-}\left(s_{m}\right)$ are obtained through iteration. Starting values for $n_{s g}\left(s_{m}\right), n_{+}\left(s_{m}\right)$ and $n_{-}\left(s_{m}\right)$ are $n_{s}, n_{+}$and $n_{-}$. From $s_{m}$, the critical radius for each aerosol mode and the associated cut-off radius, i.e., the smallest dry aerosol radius activated, are obtained following Pruppacher and Klett (1997). These are then used to recalculate $n_{s g}\left(s_{m}\right), n_{+}\left(s_{m}\right)$ and $n_{-}\left(s_{m}\right)$ with which a next iteration is started. We found that convergence is generally reached within four iterations. Finally, CDNC is defined by the particles whose size exceeds the cut-off radius, i.e., $n_{s g}\left(s_{m}\right)$.

Acknowledgements. The study contributes to the EU project PHOENICS ("Particles of Human Origin Extinguish Natural solar Irradiance in the Climate System"; EVK2-CT-2001-00098). We thank SARA Reken- en Netwerkdiensten in Amsterdam for use of their supercomputer and acknowledge the use of the Ferret program for the graphics (http://www.ferret.noaa.gov).

Edited by: B. Kärcher

\section{References}

Abdul-Razzak, H. and Ghan, S. J.: A parameterization of aerosol activation, 2, Multiple aerosol types, J. Geophys. Res., 105, 6837-6844, doi:10.1029/1999JD901161, 2000.

Abdul-Razzak, H. and Ghan, S. J.: A parameterization of aerosol activation, 3, Sectional representation, J. Geophys. Res., 107, 4026, doi:10.1029/2001JD000483, 2002.

Albrecht, B. A.: Aerosols, cloud microphysics and fractional cloudiness, Science, 245, 1227-1230, 1989.

Bauer, S. E. and Koch, D.: Impact of heterogeneous sulfate formation at mineral dust surfaces on aerosol loads and radiative forcing in the Goddard Institute for Space Studies general circulation model, J. Geophys. Res., 110, D17 202, doi:10.1029/2005JD005870, 2005.

Boucher, O. and Lohmann, U.: The sulfate-CCN-cloud albedo effect: A sensitivity study with two general circulation models, Tellus 47B, 281-300, 1995.

Easter, R. C., Ghan, S. J., Zhang, Y., Saylor, R. D., Chapman, E. G., Laulainen, N. S., Abdul-Razzak, H., Leung, L. R., Bian, X., and Zaveri, R. A.: MIRAGE: Model description and evaluation of aerosols and trace gases, J. Geophys. Res., 109, D20 210, doi:10.1029/2004JD004571, 2004.

Ervens B., Feingold, G., Frost, G. J., and Kreidenweis, S. M.: A modeling study of aqueous production of dicarboxylic acids: 1. Chemical pathways and speciated organic mass production, J. Geophys. Res., 109, D15 205, doi:10.1029/2003JD004387, 2004.

Facchini, M. C., Mircea, M., Fuzzi, S., and Charlson, R. J.: Cloud albedo enhancement by surface-active organic solutes in growing droplets, Nature, 401, 257-259, 1999.

Feingold, G. and Kreidenweis, S.: Cloud processing of aerosol as modeled by a large eddy simulation with coupled microphysics and aqueous chemistry, J. Geophys. Res, 107, 4687, doi:10.1029/2002JD002054, 2002. 
Flossmann, A. I.: The scavenging of two different types of marine aerosol particles using a two-dimensional detailed cloud model, Tellus B, 43, 301-321, 1991.

Fountoukis, C. and Nenes, A.: Continued development of a cloud droplet formation parameterization for global climate models, J. Geophys. Res., 110, D11 212, doi:10.1029/2004JD005591, 2005.

Ghan, S. J., Easter, R. C., Hudson, J., and Breon, F.-M.: Evaluation of aerosol indirect radiative forcing in MIRAGE, J. Geophys. Res., 106, 5317-5334, 2001.

Guo, H., Penner, J. E., Herzog, M., and Liu, X.: Comparison of the vertical velocity used to calculate the cloud drop number concentration in a cloud-resolving and a global climate model, Fourteenth ARM Science team Meeting proceedings, Albuquerque, New Mexico, 22-26 March 2004.

Han, Q., Rossow, W. B., and Lacis, A. A.: Near-global survey of effective droplet radii in liquid water clouds using ISCCP data, J. Climate, 7, 465-497, 1994

Hagemann S., Arpe, K., and Roeckner, E.: Validation of the hydrological cycle in the ECHAM5 model, J. Climate, in press, 2006.

Hänel, G.: The role of aerosol properties during the condensational stage of cloud: a reinvestigation of numerics and microphysics, Beitr. Phys. Atmosph., 60, 321-339, 1987.

Hegg, D. A. and Larson, T. V.: The effects of microphysical parameterization on model predictions of sulfate production in clouds, Tellus, B42, 272-284, 1990.

Jones, A., Roberts, D., Woodage, M., and Johnson, C.: Indirect sulphate aerosol forcing in a climate model with an interactive sulphur cycle, J. Geophys. Res., 106, 20 293-20 310, 2001.

Kreidenweis, S. M., Walcek, C. J., Feingold, G., Gong, W., Jacobson, M. Z., Kim, C., Liu, X., Penner, J. E., Nenes, A., and Seinfeld, J. H.: Modification of aerosol mass and size distribution due to aqueous phase $\mathrm{SO}_{2}$ oxidation in clouds: Comparisons of several models, J. Geophys. Res., 108, 4213, doi:10.1029/2002JD002697, 2003.

Kroll, J. H., Nga, L., Murphy, S. M., Flagan, R. C., and Seinfeld, J. H.: Secondary organic aerosol formation from isoprene photooxidation under high- $\mathrm{NO}_{\mathrm{x}}$ conditions, Geophys. Res. Lett., 32, L18 808, doi:10.1029/2005GL023637, 2005.

Kulmala, M., Laaksonen, A., Korhonen, P., Ahonen, T., and Baret, J.: The effect of atmospheric nitric acid vapor on cloud condensation nucleus activation, J. Geophys. Res., 98, 22 949-22 958, 1993.

Lance, S., Nenes, A., and Rissman, T. A.: Chemical and dynamical effects on cloud droplet number: Implications for estimates of the aerosol indirect effect, J. Geophys. Res., 109, D22 208, doi:10.1029/2004JD004596, 2004.

Lelieveld, J. and Crutzen, P. J.: Influences of cloud photochemical processes on tropospheric ozone, Nature, 343, 227-233, 1990.

Lim, H. J., Carlton, A. G., and Turpin, B. J.: Isoprene forms secondary organic aerosol through cloud processing: model simulations, Environ. Sci. Technol., 39, 4441-4446, 2005.

Lohmann, U. and Roeckner, E.: Design and performance of a new cloud microphysics scheme developed for the ECHAM4 general circulation model, Clim. Dyn., 12, 557-572, 1996.

Lohmann, U., Feichter, J., Chuang, C. C., and Penner, J. E.: Predicting the number of cloud droplets in the ECHAM GCM, J. Geophys. Res., 104, 9169-9198, 1999.
Lohmann, U. and Feichter, J.: Global indirect aerosol effects: a review, Atmos. Chem. Phys., 5, 715-737, 2005, http://www.atmos-chem-phys.net/5/715/2005/.

Maria, S. F., Russell, L. M., Gilles, M. K., and Myneni, S. C. B.: Organic aerosol growth mechanisms and their climate-forcing implications, Science, 306, 1921-1924, 2004.

Meskhidze, N., Nenes, A., Conant, W. C., and Seinfeld, J. H.: Evaluation of a new cloud droplet activation parameterization with in situ data from CRYSTAL-FACE and CSTRIPE, J. Geophys. Res., 110, D16 202, doi:10.1029/2004JD005703, 2005.

Nenes, A. and Seinfeld, J. H.: Parameterization of cloud droplet formation in global climate models, J. Geophys. Res., 108, 4415, doi:10.1029/2002JD002911, 2003.

O’Dowd, C. D., Facchini, M. C., Cavalli, F., Ceburnis, D., Mircea, M., Decesari, S., Fuzzi, S., Yoon, Y. J., and Putaud, J.-P.: Biogenically-driven organic contribution to marine aerosol, Nature, 431, 676-680, 2004.

Pruppacher, H. R. and Klett, J. D.: Microphysics of clouds and precipitation, Kluwer Acad. Dordrecht, The Netherlands, p. 167190, 1997.

Roelofs, G. J.: A cloud chemistry sensitivity study and comparison of explicit and bulk cloud model performance, Atmos. Environ., 27A, 2255-2264, 1993.

Roelofs, G. J., Ganzeveld, L. G., and Lelieveld, J.: Simulation of global sulfate distribution and the influence on effective cloud drop radii with a coupled photochemistry-sulfur cycle model, Tellus 50B, 224-242, 1998.

Roelofs, G. J. and Jongen, S.: A model study of the influence of aerosol size and chemical properties on precipitation formation in warm clouds, J. Geophys. Res., 109, D22 201, doi:10.1029/2004JD004779, 2004.

Rotstayn, L. D. and Lohmann, U.: Simulation of the tropospheric sulfur cycle in a global model with a physically based cloud scheme, J. Geophys. Res. 107, 4592, doi:10.1029/2002JD002128, 2002.

Spracklen, D. V., Pringle, K. J., Carslaw, K. S., Chipperfield, M. P., and Mann, G. W.: A global off-line model of size-resolved aerosol microphysics: I. Model development and prediction of aerosol properties, Atmos. Chem. Phys., 5, 2227-2252, 2005, http://www.atmos-chem-phys.net/5/2227/2005/.

Stier, P., Feichter, J., Kinne, S., Kloster, S., Vignati, E., Wilson, J., Ganzeveld, L., Tegen, I., Werner, M., Balkanski, Y., Schulz, M., and Boucher, O.: The aerosol-climate model ECHAM5-HAM, Atmos. Chem. Phys., 5, 1125-1156, 2005, http://www.atmoschem-phys.net/5/1125/2005/.

Vignati, E., Wilson, J., and Stier, P.: M7: An efficient size-resolved aerosol microphysics module for large-scale aerosol transport models, J. Geophys. Res., 109, D22 202, doi:10.1029/2003JD004485, 2004.

Wild, M. and Roeckner, E.: Radiative fluxes in the ECHAM5 general circulation model, J. Climate, in press, 2006.

Wilson, J., Cuvelier, C., and Raes, F.: A modeling study of global mixed aerosol fields, J. Geophys. Res., 106, 34 081-34 108, 2001.

Wurzler, S. C., Levin, Z., and Reisin, T. G.: Cloud processing of dust particles and subsequent effects on drop size distributions, J. Aerosol. Sci., 28, 427-428, 1997. 